УДК 101:304.2

$10.17213 / 2075-2067-2021-3-102-109$

\title{
РОЛЬ РЕЛИГИИ В СТОЛКНОВЕНИИ КУЛЬТУРНО-ЦИВИЛИЗАЦИОННЫХ КОНФЛИКТОВ
}

\author{
(C) 2021 г. Н. А. Шилина*, В. А. Черярин*, С. И. Самыгин **
}

\begin{abstract}
"Южный федеральный университет, г. Ростов-на-Дону, Россия
** Ростовский государственный экономический университет (РИНХ), 2. Ростов-на-Дону, Россия
\end{abstract}

Целью исследования является определение роли религии в столкновении культурноцивилизационных конфликтов, выявление причин религиозных конфликтов и параллельное проведение аналитической деятельности на основе исследовательских работ с иелью разработки приемов превентивного недопущения и разрешения религиозных конфликтов.

Методологическую базу исследования представляет опыт создателя теории столкновения ичивилизаџий С. Хантингтона и концеепџия глобализаџฺи, которая усиливает теорию столкновения цчивилизаций.

Результаты исследования выражаются в следующих постулатах: 1) конфликтьл между культурами и цивилизациями неизбежны и религия играет в них важную роль; 2) религия сама является мощчным источником для порождения культурно-иивилизационных конфликтов; 3) религия может стать триггером конфликтов в странах, принадлежащих к одной ичивилизачии; 4) религиозные различия могут расколоть одну отдельно взятую страну.

Перспективу исследования составляет дальнейшее конфликтологическое исследование приобретаемого опыта воюющих стран в поиске и внедрении новых инструментов принесения мира.

Ключевые слова: религия; конфликты; культура; культурные иенности; культурноцчивилизачионные конфликты; столкновения цุивилизаџий; Хантингтон.

\section{THE ROLE OF RELIGION IN THE CLASH OF CIVILIZATIONAL CONFLICTS}

\author{
(C) 2021 N. A. Shilina*, V. A. Cheryarin*, S. I. Samygin** \\ "Southern Federal University, Rostov-on-Don, Russia \\ ${ }^{* *}$ Rostov State University of Economics (RSUE), Rostov-on-Don, Russia
}

The purpose of the study is to definition of the role of religion in the clash of cultural and civilizational conflicts, the identity of the causes of religious conflicts and, in parallel, to conduct analytical activities based on research work, in order to develop methods of preventive prevention and resolution of religious conflicts.

The methodological basis of the research is represented by the experience of the creator of the theory of the clash of civilizations, S. Huntington and the concept of globalization, which reinforces the theory of the clash of civilizations.

The research results are expressed in the following postulates: 1) conflicts between civilizations are inevitable and religion plays an important role in them; 2) religion itself is a powerful source 
of conflict; 3) religion can become a trigger of conflicts within countries belonging to the same civilization; 4) religious differences can split one separate country.

The prospect of the research is a further conflictological study of the experience gained by the belligerent countries in the search and implementation of new tools for bringing peace.

Key words: religion; conflicts; culture; cultural values; cultural and civilizational conflicts; clashes of civilizations; Huntington.

Введение. В настоящее время религия интегрирована практически во все сферы жизни человека и социальные институты. В связи с этим все конфликты, которые касаются человека, отражаются в религии. Целесообразно указать, что существуют и обратная связь: если конфликты связаны с религией, то они могут перерасти и в социальные конфликты, оказать негативное влияние на общественные отношения [1].

Сегодня смысл религиозности трансформируется. Данные изменения обусловлены трансформациями, которые наблюдаются как в самом мировом сообществе, так и в сознании населения [2].

Религиозные конфликты приводят к военным, вооруженным конфликтам, которые уничтожают государства, изменяют границы, перекраивают карты, разрушают семьи и общество в целом. Также религиозные конфликты раскалывают объединения, создают почву для нетерпимости и насилия. Разумеется, всем будет лучше, если деструктивных конфликтов удастся избежать. Даже правители стран зачастую вынуждены идти на поводу у огромных фанатичных масс, появление которых является еще одним следствием религиозных конфликтов. Фанатизм запускает в движение механизмы, перемалывающие в труху судьбы людей, которым не повезло попасть под него. Для фанатиков никто, кроме священнослужителей, не имеет ни малейшего авторитета. Но и священники могут быть запросто убиты фанатиками, если совершат непотребные, по их мнению, действия.

Специфика религиозных конфликтов. Религиозные конфликты исследуются учеными из разных областей науки. Психологи, социологи, политологи, конфликтологи, историки обращаются к данной проблематике, делая эту тему междисциплинарной. В рамках каждой из наук исследователи находят свои аспекты данного поля исследования и рассматривают религиозные конфликты при помощи различных теоретических подходов.

Многие исследователи отмечают, что религиозные конфликты являются видом социальных конфликтов [3]. Элементы, которые входят в структуру религиозных конфликтов, обладают религиозными основаниями [4].

Причинами религиозных конфликтов могут стать разные факторы как внутреннего, так и внешнего характера.

Чаще всего исследователи подразумевают под религиозными конфликтами противоборство людей, которые представляют различные вероисповедания, или же противоречия, возникающие в группе людей представителей одного вероисповедания. Оcновой религиозного конфликта может быть нетерпимость к идеям чужой культуры [5].

В рамках данной работы религиозный конфликт подразумевает под собой столкновение представителей, обладающих разными религиозными взглядами. Эти столкновения связаны с тем, что данные представители стремятся реализовать свои интересы через воздействие на властные структуры.

Основной особенностью религиозных конфликтов является то, что они затрагивают не только социально-политическую и экономическую жизнедеятельность, но, прежде всего, духовную, социокультурную жизнь людей, организуются в т.н. новые религиозные движения $[6,7,8]$. По мнению И. В. Лучшевой, религиозный конфликт может приобрести политический контур, если взаимодействие акторов происходит в определенных общественно-политических и социально-экономических условиях [1].

Столкновение цивилизаций в концепции С. Хантингтона. Какие объективные об- 
стоятельства способствовали формированию концепции Сэмюэля Хантингтона? Для ответа на данный вопрос необходимо обратить взор на столкновение цивилизаций в творчестве этого ученого.

Американский политолог С. Хантингтон разработал концепцию столкновения цивилизаций в 1993 г. и развивал ее вплоть до ухода из жизни в 2008 г. В данной концепции узловым элементом теоретических построений и измышлений ученого является культура. Ученый небезосновательно полагал, что глобальные трансформации влияют на перестройку мирового порядка. Глобальные трансформации происходят из-за изменений, которые настигают государственные структуры, а также из-за ценностных трансформаций [9]. Данные обстоятельства оказывают влияние на социокультурную идентичность, источники которой заложены в самом человеке. По мнению М.Н. Коротковой, люди очень часто испытывают недоверие к тем, кто обладает отличительными от них признаками, так как считают, что это может являться причиной угрозы их жизни или здоровью [10]. Так происходит и среди современных государств. В настоящее время одной из особенностей мировой глобализации выступает недоверие государств друг другу. Следует отметить тот факт, что при разрешении одного конфликта могут быть запущены новые конфликты, которые начнут действовать с еще большей силой. По мнению С. Хантингтона, одним из главных врагов западной цивилизации выступает исламская цивилизации [11].

По мнению С. Хантингтона, причина многих конфликтов кроется в культуре, возникшей после того, как в мире произошел распад социалистической системы [11]. Данный исследователь полагал, что любой глобальный конфликт неминуемо будут завершаться конфликтом цивилизаций [12].

С. Хантингтон подчеркивал ведущую роль религии в культурно-цивилизационных конфликтах. Он считал, что в ближайшем будущем конфликты между нациями-государствами сменятся конфликтами между цивилизациями. Всего он выделил десять цивилизаций: западную цивилизацию, латинскую цивилизацию, японскую цивилизацию, синскую цивилизацию, буддийскую цивилизацию, индуистскую цивилизацию, исламскую цивилизацию, православную цивилизацию и цивилизацию англоязычных стран Карибского бассейна. Хантингтон подчеркивал, что причиной этого являются следующие различия между цивилизациями: язык, культура, культурные ценности, традиции и религия [11].

С. Хантингтон подчеркивал также, что религия является ключевым различием между цивилизациями, говоря о том, что люди разных цивилизаций по-разному смотрят на отношения между Богом и человеком, индивидом и группой, гражданином и государством. Люди разных религиозных взглядов чаще всего имеют совершенно разные представления о равенстве, иерархии, праве и обязанности. С. Хантингтон справедливо отмечал, что такие различия формируются в течение многих веков и не исчезнут в ближайшее время [11].

Теория «столкновения цивилизаций» во взаимосвязи с концепцией глобализации. В связи с тем, что современные государства приступили к поиску нового врага для того, чтобы консолидироваться в борьбе с этим врагом за глобальные ресурсы географического пространства, появляется теория столкновения цивилизаций. Данное обстоятельство в очередной раз подчеркивает идеи С. Хантингтона, связанные с тем, что столкновение цивилизаций обязательно приводит к экспансии Запада. По мнению исследователя Н.А. Комлева, «западная сверхдержава и ее союзники обладают мощью, не встречающей равнозначного глобального противодействия, т.е. могут навязывать свои ценности и экономические проекты своих суперкорпораций всем остальным. Теоретическим подкреплением глобальной экспансии Запада является концепция глобализации» [12, с. 36]. Глобализационная концепция оказывает влияние на теорию столкновения цивилизаций. Исходя из этого, политика Запада - это следствие объективного закона глобальной взаимозависимости экономик и культур.

В своей монографии С. Хантингтон подчеркивал: «Подстегиваемая модернизацией, идет перестройка глобального политического пространства по культурному принципу. Народы и страны родственных культур сближаются. Народы и страны различных культур, напротив, отдаляются друг от друга. 
Союзы и блоки, определившиеся идеологией и отношениями сверхдержав, сменяются союзами, диктуемыми принадлежностью к той или иной культуре и цивилизации. Ускоряются процессы, направленные на приведение политических границ в соответствие с культурными. Сообщества, объединяемые общей культурой, приходят на смену блокам времен холодной войны, а линии тектонических разломов между цивилизациями становятся осями противостояний и столкновений мировой политики» [11, с. 27].

С. Хантингтон повествовал о том, что конфликты на почве религии намного более остры, чем все прочие. Эти конфликты усугубляются тем, что нельзя одновременно принадлежать к двум и более вероисповеданиям, а остроты им придает то, что за неправильный ответ на вопрос, к какой религии вы принадлежите, можно подвергнуться репрессии. Кроме того, страны и нации разных государств, принадлежащие к одной цивилизации и имеющие общую религию, зачастую сплачиваются против иноверцев и стран других цивилизаций [11].

Данное обстоятельство прослеживается и в экономике. Например, многие страны стали вести экономическое сотрудничество на почве мусульманской религии (Иран, Пакистан, Турция и другие). Также можно привести еще один пример: связь Китая и Гонконга укрепилась за счет общности культуры. Идеологические различия вытесняются за счет общности культур.

Также прослеживается усиление экономического регионализма. Отметим, что за девятилетний период с 1980 г. по 1989 г. доля внутрирегиональной торговли возрастает на несколько процентов: в Европе на 9\%, в ЮгоВосточной Азии на 7\%, в Северной Америке на 4\%. Таким образом, можно отметить, что наблюдается экономический регионализм.

Хантингтон также отмечал, что после конца холодной войны идеология перестала быть причиной конфликтов, уступив место религии и культуре. По мнению ученого, разногласия по поводу прав человека, эмиграции, возникают из-за определенных различий людей.

С. Хантингтон полагал, что существует два уровня, на которых разворачивается конфликт. Нижний уровень показывает, что люди борются за территории и ресурсы, а на верхнем уровне государства с разными религиями стараются захватить власть друг над другом и над другими государствами.

Например, если раньше во время холодной войны в кровопролитии в Европе играли решающую роль политические и идеологические мотивы, то после падения «железного занавеса» Европа оказалась разделена на несколько блоков: блок западного христианства, православный блок и исламский блок.

Несмотря на религиозные противоречия, протестанты и католики имеют общий исторический опыт и схожесть экономик, что предопределяет их сближение. Этот пример наиболее ярко иллюстрирует, что даже религиозную вражду можно преодолеть при наличии определенных условий. По сути, некогда разделивший Европу «железный» занавес сменился «бархатным» занавесом.

Попытки обратить иноверцев в свою религию совершались неоднократно. Примером этого можно считать и походы арабов в Европу, и крестовые походы, совершавшиеся с XI по XIII вв., и походы турков-османов, дважды осаждавших Вену, и колонизацию стран Африки и Америки. Запад долгое время удерживал большое количество этих стран в кабальной зависимости и выкачивал из них ресурсы. Но сейчас все изменилось: колониальные империи канули в прошлое, началась ответная реакция, выражающаяся в росте терроризма $[13,14]$. Сам же Запад оказался в зависимости от стран Персидского залива, которые снабжают его нефтью. В то же время Запад создает государство Израиль для противовеса арабским странам. В 1956 г. произошло вторжение западных войск в Египет. 1958 г. хранит в себе события вторжения американцев в Ливан, после чего они часто туда вторгались. А в 1990 г. противостояние дошло до точки кипения. США отправили в Персидский залив войска, чтобы защищать одних арабов от других. Этот пример наглядно показывает, что общность религии и культуры вовсе не гарантирует мира и сближения между странами.

Вооруженная борьба между западными странами и исламским миром не сбавляет обороты. Присутствие вооруженных сил Запада в Персидском заливе задело за живое многих арабов и породило у них чувство обиды. 
Демографическая обстановка также даёт о себе знать. Резкий рост населения Северной Африки и повальная эмиграция оттуда в Европу вызывают резкое неприятие и рост расистских настроений. В то же время в Европе смягчаются настроения по отношению к другим мигрантам. Всё это лишь усугубляет конфликт между Западом и Исламскими странами. Но этот конфликт не ограничивается противостоянием арабов с Европой и США. С древности можно наблюдать взаимодействие арабо-исламской цивилизации с чернокожим населением Юга - представителями язычества и христианства, что можно наблюдать в рамках восстаний в Чаде, в войне в Нигерии. Ещё раньше всё это воплощалось в конфликтах между арабами-работорговцами и их жертвами. Но это противостояние резко обострилось после речи папы Иоанна-Павла II в феврале 1993 г. в Хартуме, который в своем выступлении раскритиковал антихристианские действия, предпринимаемые суданским правительством. Этот пример доказывает, сколь высокую роль играют религиозные лидеры в подобных конфликтах.

Но противостояние православных и мусульман происходит и в других местах: столкновения в Боснии и Сараево, военные действия между Арменией и Азербайджаном, Осетией и Ингушетией, военные действия российских войск на территории Кавказа и Средней Азии. Именно религия становится яблоком раздора в рамках этнической самоидентификации $[15,16,17]$.

Однако в других азиатских местах тоже существуют подобные конфликты. Например, в Индии, конкурирующей с Пакистаном из-за религиозных соображений, прослеживается усиление в борьбе таких группировок, как радикальные индуистские и мусульманское меньшинство. Вспомним событие, которое произошло в конце 1992 года, когда была разрушена мечеть Айодха. Именно тогда возник вопрос, связанный с тем, сможет ли Индия остаться светским и демократическим государством, или же это событие повлечет то, что Индия станет индуистским. В то же время Китай беспощаден в Тибете и жесток по отношению к религиозным меньшинствам. А противоречия между Китаем и США по самым разным вопросам только усиливаются, что непременно приведёт к конфрон- тации этих двух держав. Кроме того, между Японией и США имеется экономический конфликт, который только подогревается религиозными различиями. Экономические различия США с Европой не менее глубоки, однако ввиду общей религии и культуры, намного менее остры. Это показывает, что экономические разногласия также зависят от культурно-религиозной составляющей.

Заключение. Таким образом, столкновение цивилизаций становится доминирующим фактором мировой политики, и религия с ее религиозными ценностями играет крайне важную роль в столкновениях между цивилизациями, странами, группировками и отдельными людьми. Единоверцы часто готовы помогать друг другу, в том числе в войне с теми, кого они считают неверными. И в то же время люди разных религий вызывают друг у друга раздражение, формируя протестные настроения и перерастая в вооруженные конфликты. Из всего сказанного выше следует, что религиозные конфликты неискоренимы, а обратить весь мир в одну религию не представляется возможным.

\section{Литература}

1. Лучшева Л.В. Религиозные отношения и религиозный конфликт // Вестник экономики, права и социологии. - 2017. - №4. C. 283-286.

2. Сидоренко Н. С. Особенности исследования религии в современном обществе // Научный вестник Южного института менеджмента. - 2014. - №3. - С. 93-98.

3. Гафиатулина Н.Х., Самыгин С.И. Социальная коммуникация в профилактике конфликтов. Учебно-методическое пособие для студентов. - М., 2021.

4. Матеикая А. В., Самыгин С.И., Эгильский Е. Э., Морозова О.М. Религиоведение учебное пособие. - Ростов-на-Дону, 2009.

5. Shakhbanova M.M., Velikorodnaya I.V., Starostin A. M., Tishkin D. N., Samygin S.I. The factors of escalaion of ethno-political tension in the south of Russia // Public Administration and Regional Management in Russia. Challenges and Prospects in a Multicultural Region. Ser. «Contributions to Economics». - Switzerland, 2020. - P. 405-415. 
6. Васильева Е.Н. Новые религиозные движения: понятие и специфика // Вестник Ленинградского государственного университета им. А.С. Пушкина. — 2016. - №1. C. $1-11$.

7. Гафиатулина Н.Х., Самыгин С.И. Религиозные установки как элемент управления ценностными ориентациями современной молодежи // Экономические проблемы России и региона. Ученые записки. Ростовский государственный экономический университет (РИНХ). - Ростов-на-Дону, 2019. C. 217-225.

8. Белов М.Т., Гафиатулина Н.Х., Самыгин С.И. Управление религиозными ориентирами в сознании современной молодежи // Экономические проблемы России и региона. Ученые записки. Ростовский государственный экономический университет (РИНХ). — Ростов-на-Дону, 2019. С. 186-193.

9. Кирсанов А.И. С. Хантингтон о «столкновении цивилизаций» в контексте глобальных трансформаций // Философия и общество. - 2008. - №3. - С. 32-43.

10. Короткова М.Н. «Столкновение цивилизаций» С. Хантингтона: в поисках идентичности в современном мире // Вестник Пермского университета. - 2011.

11. Хантингтон C. Столкновение цивилизаций? - М., 2003. - 603 с.

12. Комлева Н.А. Концепция столкновение цивилизаций: прагматический аспект // Пространство и Время. - 2011. — №2 (4). C. 35-37.

13. Гафиатулина Н.Х., Брусенщева Д.М. Террористическая деятельность: сущностные признаки и факторы детерминации // Гуманитарные, социально-экономические и общественные науки. - 2018. - №3. C. 23-25.

14. Гафиатулина Н.Х., Топорков Г. А. Модель преступного поведения: социологический анализ // Гуманитарные, социальноэкономические и общественные науки. 2018. - №5. - С. 25-27.

15. Самылин С.И., Верещчагина А.В., Рачипа $A$. $B$. Вызовы и угрозы религиозного радикализма национальной безопасности постсекулярных обществ // Экономические и гуманитарные исследования регионов. 2016. 一 №2. - С. 103-107.
16. Семенюк A.B. Международные вооруженные конфликты и пути их урегулирования: методологические аспекты изучения проблемы // Вестник Пермского университета. - 2016. - №3. - С. 109-124.

17. Касьянов В.В., Самыгин С. И., Шилина Н.A. Социокультурные культурные последствия российской революции // Гуманитарные, социально-экономические и общественные науки. — 2017. — №10.

\section{References}

1. Luchsheva L. V. Religioznye otnoshenija i religioznyj konflikt [Religious relations and religious conflict] // Vestnik jekonomiki, prava i sociologii [Bulletin of Economics, Law and Sociology]. — 2017. — №4. - Pp. 283-286.

2. Sidorenko N.S. Osobennosti issledovanija religii $\mathrm{v}$ sovremennom obshhestve [Features of the study of religion in modern society] // Nauchnyj vestnik Juzhnogo instituta menedzhmenta [Scientific Bulletin of the Southern Institute of Management]. — 2014. — №3. - Pp. 93-98.

3. Gafiatulina N.H., Samygin S.I. Social'naja kommunikacija $\mathrm{v}$ profilaktike konfliktov. Uchebno-metodicheskoe posobie dlja studentov [Social communication in conflict prevention. Educational and methodical manual for students]. - Moscow, 2021.

4. Mateckaja A.V., Samygin S.I., Jegil'skijE. Je., Morozova O. M. Religiovedenie uchebnoe posobie [Religious studies textbook]. Rostov-on-Don, 2009.

5. Shakhbanova M.M., Velikorodnaya I.V., Starostin A.M., Tishkin D.N., Samygin S.I. The factors of escalaion of ethno-political tension in the south of Russia // Public Administration and Regional Management in Russia. Challenges and Prospects in a Multicultural Region. Ser. «Contributions to Economics». - Switzerland, 2020. - P. 405-415.

6. Vasil'eva E.N. Novye religioznye dvizhenija: ponjatie i specifika [New religious movements: the concept and specifics] // Vestnik Leningradskogo gosudarstvennogo universiteta im. A.S. Pushkina [Bulletin of the Leningrad State University named after A. S. Pushkin]. 2016. - №1. - Pp. 1-11.

7. Gafiatulina N.H., Samygin S.I. Religioznye ustanovki kak jelement upravlenija cennostnymi orientacijami sovremennoj molodezhi 
[Religious attitudes as an element of management of value orientations of modern youth] // Jekonomicheskie problemy Rossii i regiona. Uchenye zapiski. Rostovskij gosudarstvennyj jekonomicheskij universitet (RINH) [Economic problems of Russia and the region. Scientific notes. Rostov State University of Economics (RSUE)]. - Rostov-on-Don, 2019. - Pp. 217-225.

8. Belov M.T., Gafiatulina N.H., Samygin S.I. Upravlenie religioznymi orientirami v soznanii sovremennoj molodezhi [Management of religious landmarks in the consciousness of modern youth] // Jekonomicheskie problemy Rossii i regiona. Uchenye zapiski. Rostovskij gosudarstvennyj jekonomicheskij universitet (RINH) [Economic problems of Russia and the region. Scientific notes. Rostov State University of Economics (RSUE)]. - Rostov-on-Don, 2019. - Pp. 186-193.

9. Kirsanov A.I.S. Hantington o «stolknovenii civilizacij» v kontekste global'nyh transformacij [Samuel Huntington's «clash of civilizations» in the context of global transformations] // Filosofija i obshhestvo [Philosophy and society]. - 2008. - №3. - Pp. 32-43.

10. Korotkova M.N. «Stolknovenie civilizacij» S. Hantingtona: v poiskah identichnosti v sovremennom mire [ «The clash of civilizations» of Samuel Huntington: the quest for identity in the modern world] // Vestnik Permskogo universiteta [Bulletin of Perm University]. - 2011.

11. Hantington $S$. Stolknovenie civilizacij? [A clash of civilizations?] — Moscow, 2003. $603 \mathrm{p}$.

12. Komleva N.A. Koncepcija stolknovenie civilizacij: pragmaticheskij aspekt [The concept of the clash of civilizations: a pragmatic aspect] // Prostranstvo i Vremja [Space and Time]. — 2011. — №2 (4). — Pp. 35-37.
13. Gafiatulina N. H., Brusenceva D. M. Terroristicheskaja dejatel'nost': sushhnostnye priznaki i faktory determinacii [Terrorist activity: essential signs and factors of determination]// Gumanitarnye, social'no-jekonomicheskie i obshhestvennye nauki [Humanities, socio-economic and social sciences]. - 2018. - №3. Pp. 23-25.

14. Gafiatulina N.H., Toporkov G.A. Model' prestupnogo povedenija: sociologicheskij analiz [Model of criminal behavior: a sociological analysis] // Gumanitarnye, social'no-jekonomicheskie i obshhestvennye nauki [Humanities, socio-economic and social sciences]. 2018. - №5. - Pp. 25-27.

15. Samygin S.I., Vereshhagina A.V., Rachipa $A$. $V$. Vyzovy i ugrozy religioznogo radikalizma nacional'noj bezopasnosti postsekuljarnyh obshhestv [Challenges and threats of religious radicalism to the national security of post-secular societies] // Jekonomicheskie i gumanitarnye issledovanija regionov [Economic and humanitarian studies of the regions]. - 2016. №2. - Pp. 103-107.

16. Semenjuk A. V. Mezhdunarodnye vooruzhennye konflikty i puti ih uregulirovanija: metodologicheskie aspekty izuchenija problemy [International armed conflicts and ways of their settlement: methodological aspects of studying the problem] // Vestnik Permskogo universiteta [Bulletin of the Perm University]. — 2016. №3. - Pp. 109-124.

17. Kas'janov V. V., Samygin S.I., Shilina N.A. Sociokul'turnye kul'turnye posledstvija rossijskoj revoljucii [Sociocultural cultural consequences of the Russian revolution] // Gumanitarnye, social'no-jekonomicheskie i obshhestvennye nauki [Humanities, socio-economic and social sciences]. — 2017. — №10. 

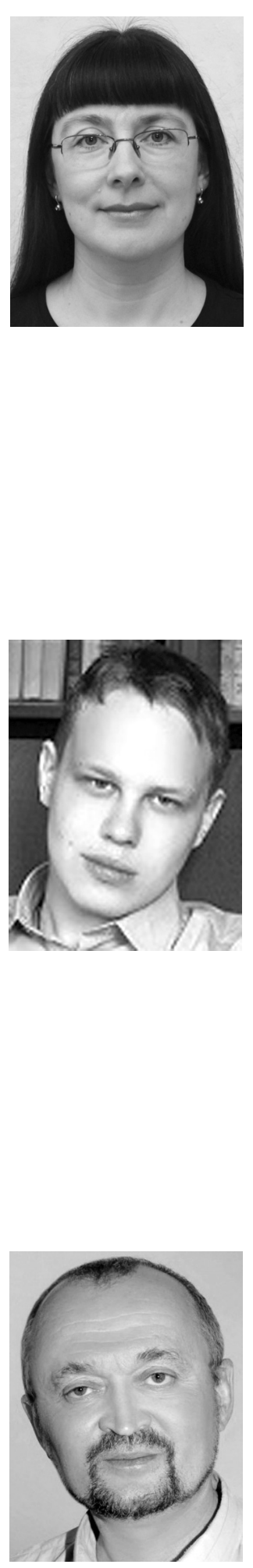

Шилина Наталья Анатольевна - кандидат социологических наук, заведующий кафедрой изобразительного искусства Академии архитектуры и искусств Южного федерального университета, член Международного союза педагогов-художников.

Shilina Natalya Anatolyevna - Candidate of Sociological Sciences, Head of the Department of Fine Arts, Academy of Architecture and Fine Arts of Southern Federal University, member of the International Union of Teachers and Artists.

344082, г. Ростов-на-Дону, ул. Горького, 75 75 Gorkogo st., 344082, Rostov-on-Don, Russia E-mail: rnd.natalia@mail.ru

Черярин Василий Александрович - студент 4-го курса специальности «Конфликтология» Института социологии и регионоведения Южного федерального университета.

Cheryarin Vasily Aleksandrovich - 4th year student of the speciality "Conflictology», Institute of Sociology and Regional Studies, Southern Federal University.

344038, г. Ростов-на-Дону, ул. Нагибина, 13

13 Nagibina st., 344038, Rostov-on-Don, Russia

E-mail: vasya.cheryarin@mail.ru

Самыгин Сергей Иванович - профессор, доктор социологических наук, профессор кафедры управления персоналом и социологии Ростовского государственного экономического университета (РИНХ).

Samygin Sergey Ivanovich - Professor, Doctor of Sociological Sciences, Professor, Department of Personnel Management and Sociology, Rostov State University of Economics (RSUE).

344002, г. Ростов-на-Дону, ул. Большая Садовая, 69 69 Bolshaya Sadovaya st., 344002, Rostov-on-Don, Russia E-mail: darya.maksimovich@gmail.com 